\title{
Morphological variation of Nile tilapia populations from major water bodies of Uganda
}

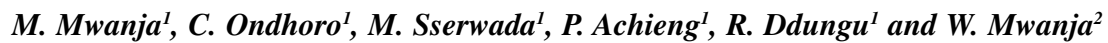 \\ ${ }^{1}$ Aquaculture Research and Development Center, Kajjansi, Box 530, Kampala, Uganda \\ ${ }^{2}$ Eccelenzia Consorzio Research and Management, Uganda, Box 27573, Kampala, Uganda
}

Author for correspondence: mwanjamt@ firi.go.ug

\begin{abstract}
With increasing demand for improved farmed Nile tilapia (Oreochromis niloticus) fish seed, there is heightened demand for quality and proven broodstock by hatchery operators throughout the country and in the East African region. Uganda, fortunately, is endowed with vast natural Nile tilapia (Oreochromis niloticus) stocks in lakes Albert, Edward and George, as well as in Albert Nile River. To aquaculturally benefit from the different attributes of different stocks/strains, it is important to establish the existing strains in a manner that is phenotypically discernible where such differences are apparent. In this study, we used a suite of morphological traits to identify strains of Nile tilapia among $\mathbf{4 2 5}$ individuals sampled from the four major water bodies, lakes Albert, Edward-George, Kyoga and Victoria. Morphological variation was investigated using multivariate approaches including principal component analysis, discriminant analysis and cluster analysis of 22 morphometric characters. These analyses indicated that there was high morphological variation among the different populations of Nile tilapia and the fish could be grouped into their respective sampled areas based on these morphological differences. Most of the variation $(86.97 \%)$ was associated with the fish body size, the peduncle length and the interorbital distances. Findings imply that there are four major Nile tilapia strains in Ugandan waters that will be subjected to aquaculture performance evaluation before being used in the genetic improvement programme to produce improved Nile tilapia fish broodstock/seed for use in fish farming. Differences among populations may reflect genetic differences and/or environmental factors.
\end{abstract}

Key words: Morphometrics, Oreochromis niloticus, strain identification

\section{Introduction}

Uganda derives substantial benefits from its aquatic and fisheries resources. The contribution to the country's total fish production from aquaculture has consistently increased, surpassing growth in both the small-scale and emerging commercial fishery sectors (Mwanja, 2005). 
Tilapia, principally Nile tilapia (Oreochromis niloticus), is the second most important farmed aquaculture species in the Uganda, after Catfish (Mwanja, 2005). The Nile tilapia is native in lakes Albert, Edward and George and introduced in the 1950s into lakes Kyoga and Victoria in Uganda (Fuerst et al., 2000). For aquaculture in Uganda, the founding stocks of Nile tilapia used as broodstock, were established from limited numbers and sources of wild genetic resources (Matsiko and Mwanja, 2008). In addition, aquaculture revamping after its collapse in the 1970s, that started in the late 1980s, had only Aquaculture Research and Development Center (ARDC)-Kajjansi as the major seed supplier. Along the way, many private hatcheries came up taking their parent stock from ARDC-Kajjansi and multiplying the same over many times without replenishing their genetic integrity (Mwanja, 2005). This has led to inbreeding of farmed Nile tilapia, and consequently poor performance of the fish in culture systems, low productivity of the culture enterprises and consequently poor returns on investment.

Addressing this problem requires turning to the country's abundant wild resources to enhance the genetic integrity of Nile tilapia broodstock, for use in aquaculture. Given the wide distribution and native range of this species in Uganda (Trewevas, 1983), there may be relatively high genetic diversity within the species and variation among populations that can be exploited to enhanced genetic integrity of farmed Nile tilapia. The process involves strain identification of this species from the different water bodies, comparison of their performance with regards to the different aquaculture traits, and selection for the best performing strains. The selected strains will then be used for Nile tilapia genetic improvement programme following a similar protocol of the development of the hugely successful GIFT strain (Genetically Improved Farmed Tilapia) (Ponzoni et al., 2007), but based on the country's native Nile tilapia genetic resources.

Weins (2004) argued that, despite the many undeniable advantages and incredible rate of advances in molecular systematics, it was still absolutely important to use morphological data in phylogenetic analyses. The objective of this study was to explore morphological phylogenetics of natural stocks of $O$. niloticus in both its native and introduced ranges in Uganda, to identify taxa or strains for possible use in aquaculture.

\section{Materials and methods}

\section{Study area}

Nile tilapia samples were taken from Lakes Albert, Kyoga, Victoria, Edward and George (Fig. 1). Lakes Albert and Edward are rift valley lakes, found on the western border of Uganda with Democratic Republic of Congo. Edward and George are connected by Kazinga channel, whereas the Victoria Nile connects lakes Victoria, Kyoga and Albert with waterfalls - Owen and Murchison on either side of Lake Kyoga.

\section{Sample collection}

Fish samples were purchased at landing sites from fishermen. A total of 425 Nile tilapia were sampled from lakes Edward, George, Albert, Kyoga and Victoria. Morphometric and biometric measurements for each of the sampled fish were done using vernier callipers, immediately after being landed. The land marks for the morphometric characters 


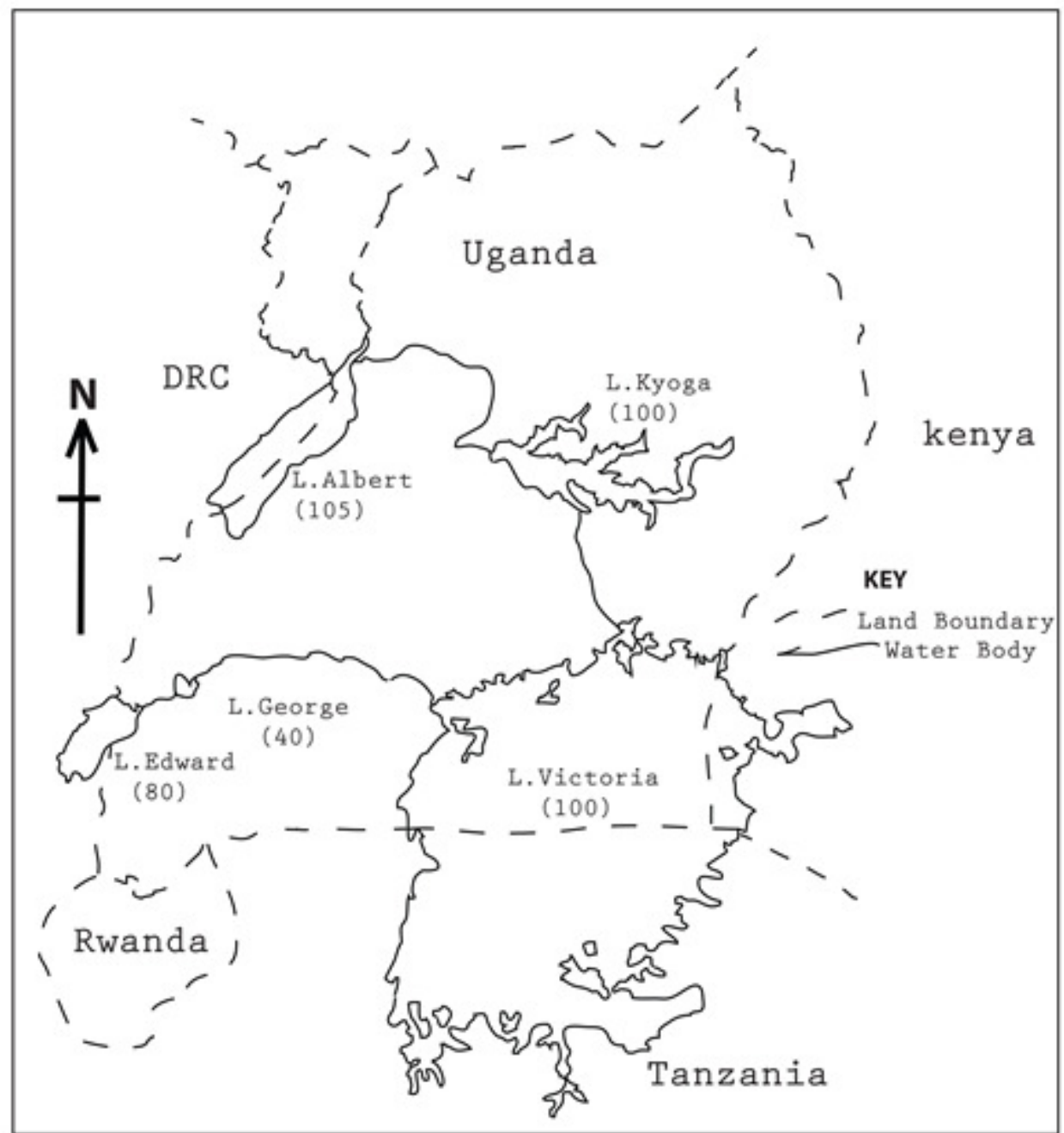

Figure 1. Map of Uganda showing the major water bodies and number Nile tilapia samples collected. Source: Freeworldmaps.net

measured (truss) included; snout, ventral junction of operculum, supra orbital, lower pectoral fin insertion, anterior dorsal fin insertion, posterior end of pelvic fin insertion, posterior end of dorsal fin insertion, anterior end anal fin insertion, dorsal caudal fin insertion, ventral caudal fin insertion (Fig. 2). The biometric measurements (non-truss) included total length, standard length, folk length, total weight, orbital distance (OBD), pectoral fine length (PFL), dorsal fin length (DFL), pelvic ventral fin length (PVFL), anal fin length (AFL) and caudal fin length (CFL) (Fig. 3).

\section{Data analysis}

To standardise data, all variables taken including TL, SL, OBD, PFL, DFL, PVFL, AFL and CFL were expressed as a percentage of TL. Also, since strains of the Nile tilapia were thought to differ in the different truss measurements, the ratios of these variables were expressed 


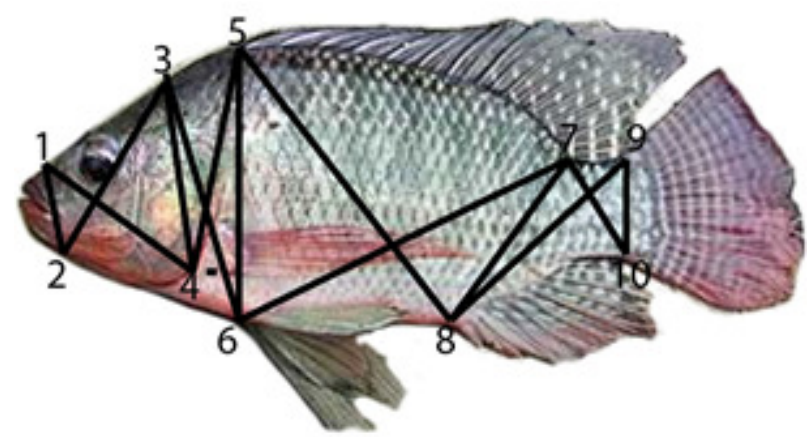

Figure 2. Showing land marks of Nile tilapia for measured morphological characters taken for this study which included: 1, Snout; 2, Ventral junction of operculum; 3, Supra orbital; 4, Lower pectoral fin insertion; 5, Anterior dorsal fin insertion; 6, Posterior end of pelvic fin insertion; 7, Posterior end of dorsal fin insertion; 8, Anterior end anal fin insertion; 9, Dorsal caudal fin insertion; 10, Ventral caudal fin insertion.

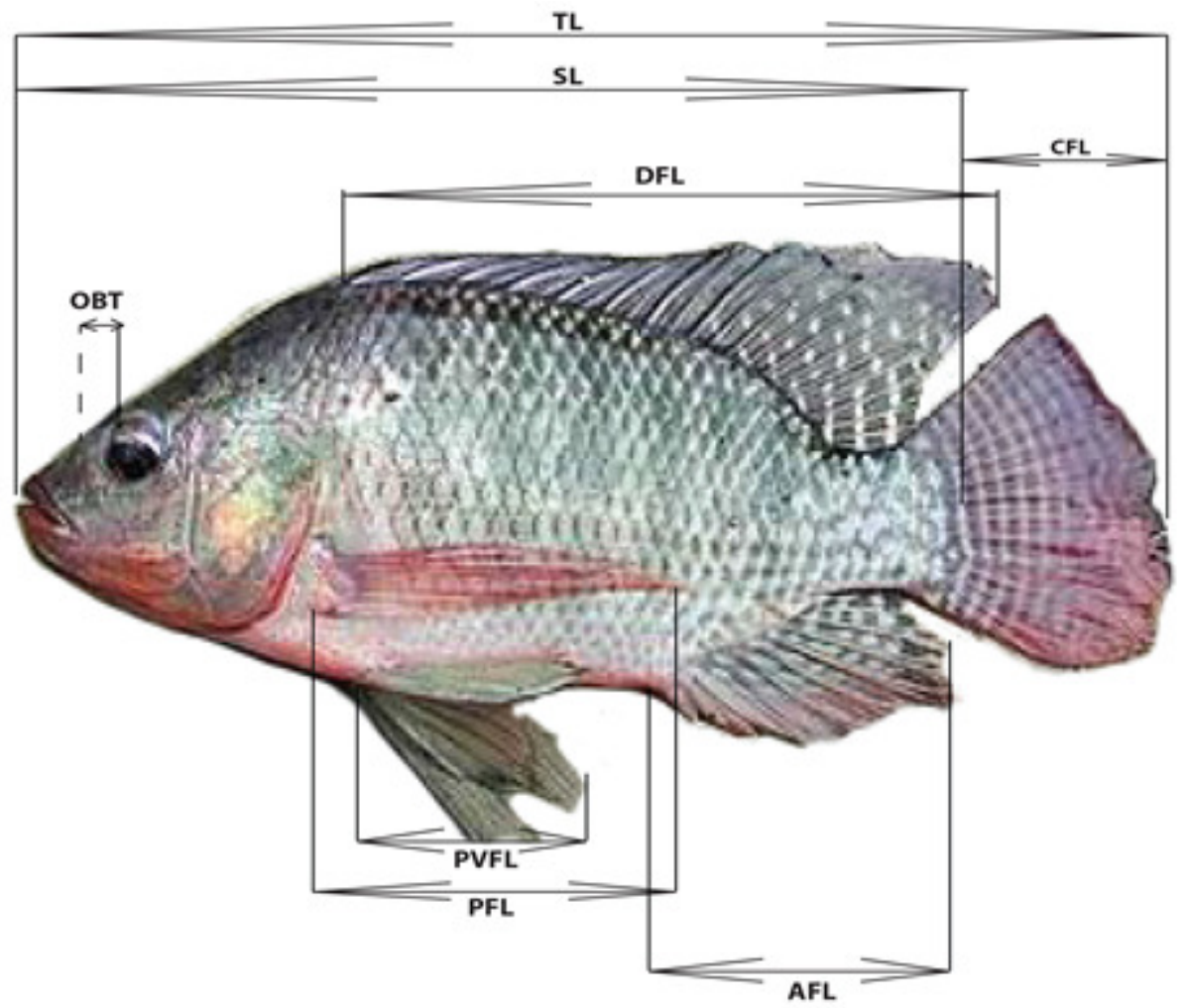

Figure 3. Showing selected non-truss measurements of tilapia taken for this study. 
as percentages. To ensure normality and homogenous variances, all obtained values were $\log _{10}$ - transformed before statistical analyses were performed. The outcomes were subjected to PCA, under multivariate data analysis using the PAST software (Hammer et al., 2001). Principal Component Analysis (PCA) was used to extract principal components from the considered variables. Using PAST, the measured morphological characters were subjected to multivariate analyses. The most significant component that contributed most to the variance was identified and was used in determining the morphological phylogenetic relationships of the $O$. niloticus of the Ugandan major water bodies. Basing on the outcome of the mixture analysis in 'PAST', all data were subjected to K-means clustering to determine non-hierarchical clustering of all the samples into the number of groups specified under the mixture analysis. For all analyses, the significance level considered was $\mathrm{P}<0.5$.

\section{Results}

The larger the Eigen value, the more of the variance in the dependent variable is explained by that principle component (PC). PC 1 explained $77.11 \%$ of the variability (Table 1). The first two principle components based on the morphometric measurements, together explained $86.97 \%$ of the variability (77.11 and 9.26\%) (Table 1), indicating that the PCA was largely successful (Hammer et al., 2001). The screw plot (Fig. 4) curve started flattened out at the second component indicating that its components 1 and 2 that were significant while the remaining components were not significant. In addition, all components with eigen values under the broken stick
Table 1. Eigen values and percentage variance for the different components of the PCA

\begin{tabular}{lll}
\hline $\mathrm{PC}$ & Eigen value & \% variance \\
\hline 1 & 15.4227 & 77.114 \\
2 & 1.85212 & 9.2606 \\
3 & 0.99369 & 4.9684 \\
4 & 0.32482 & 1.6241 \\
5 & 0.201654 & 1.0083 \\
6 & 0.177536 & 0.88768 \\
7 & 0.158559 & 0.7928 \\
8 & 0.132996 & 0.66498 \\
9 & 0.116453 & 0.58227 \\
10 & 0.102084 & 0.51042 \\
11 & 0.0864918 & 0.43246 \\
12 & 0.0778858 & 0.38943 \\
13 & 0.0669242 & 0.33462 \\
14 & 0.0573242 & 0.28662 \\
15 & 0.0494271 & 0.24714 \\
16 & 0.0462094 & 0.23105 \\
17 & 0.0408181 & 0.20409 \\
18 & 0.0332438 & 0.16622 \\
19 & 0.0312673 & 0.15634 \\
20 & 0.02779 & 0.13895 \\
\hline
\end{tabular}

are said to be insignificant (Hammer et $a l, 2001)$, only components one and two had eigen values above the broken stick (Fig. 4). Therefore, further analysis was based on these first two components -1 and 2 .

According to the loadings of component coefficients obtained for morphometric data, the most influential variables for PC 1 included TL, H, J, M and $\mathrm{N}$ (OBD) (Figs. 5 and 6). Variable $\mathrm{H}$ and $\mathrm{J}$ are involved with the fish body size, variable $\mathrm{M}$ isassociated with the peduncle length and variable $\mathrm{N}$ is associated with the inter-orbital distance. Based on the first two principle components the Nile tilapia of major water bodies of Uganda clustered in two groups as revealed by the scatter diagram (Fig. 7). This was further supported by the morphological 


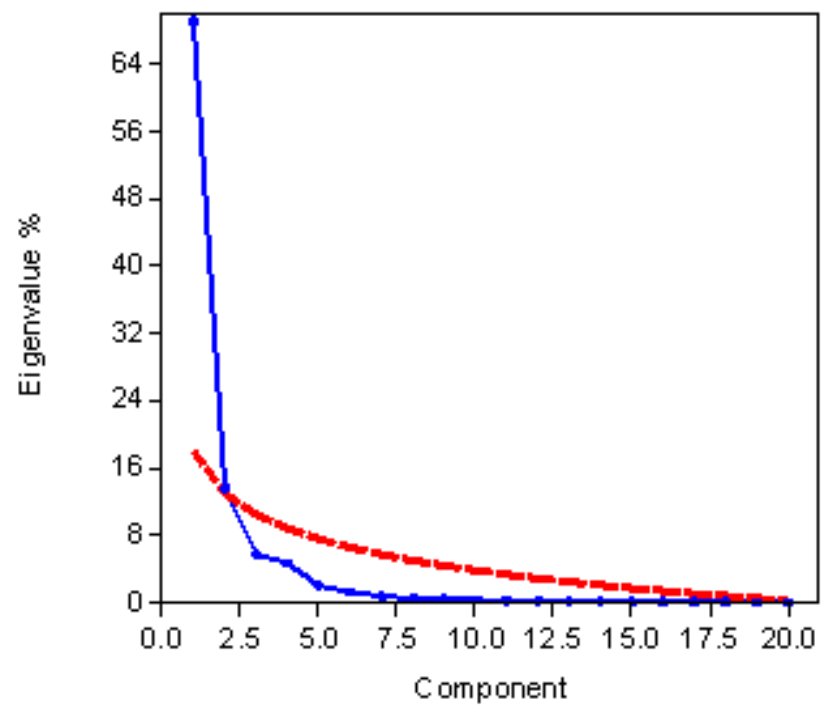

Figure 4. Scree plot of the Eigenvalues of the respective principle components.

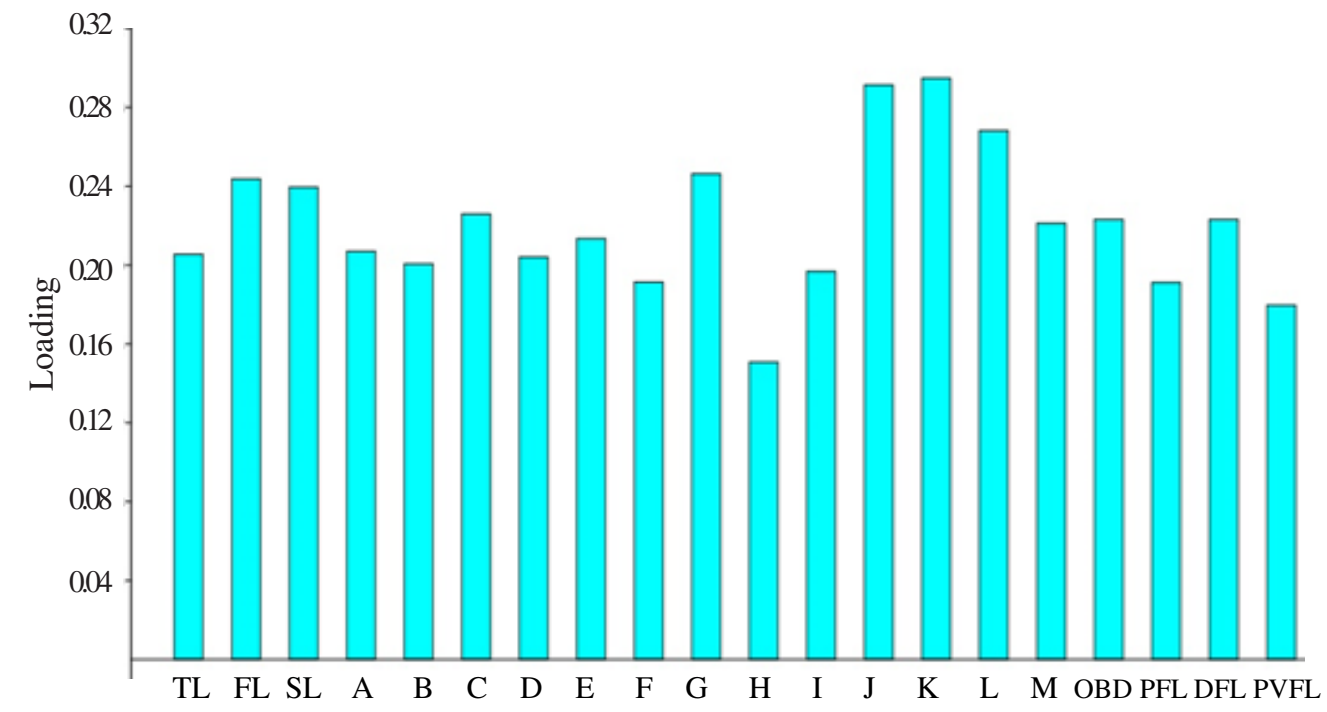

Figure 5. Graphs showing the PC1 coefficients of the different variables used in this study. 


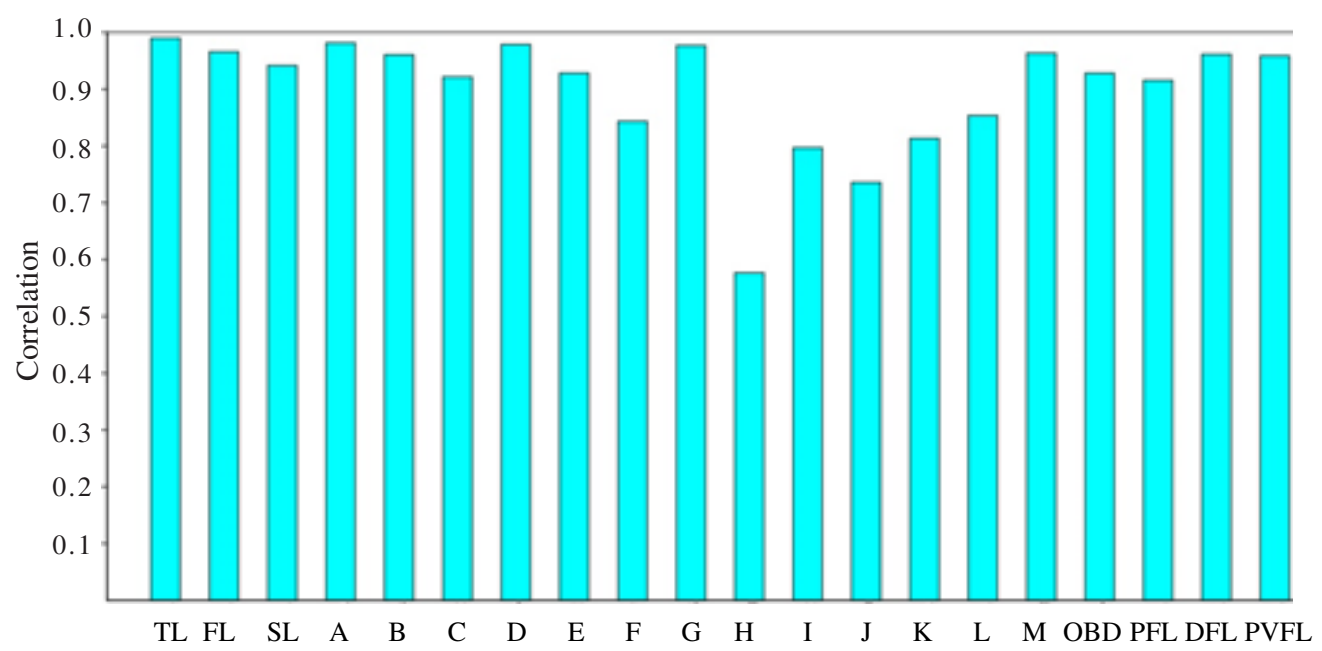

Figure 6. Graph showing the correlations between the different variables used in the study and the PC1

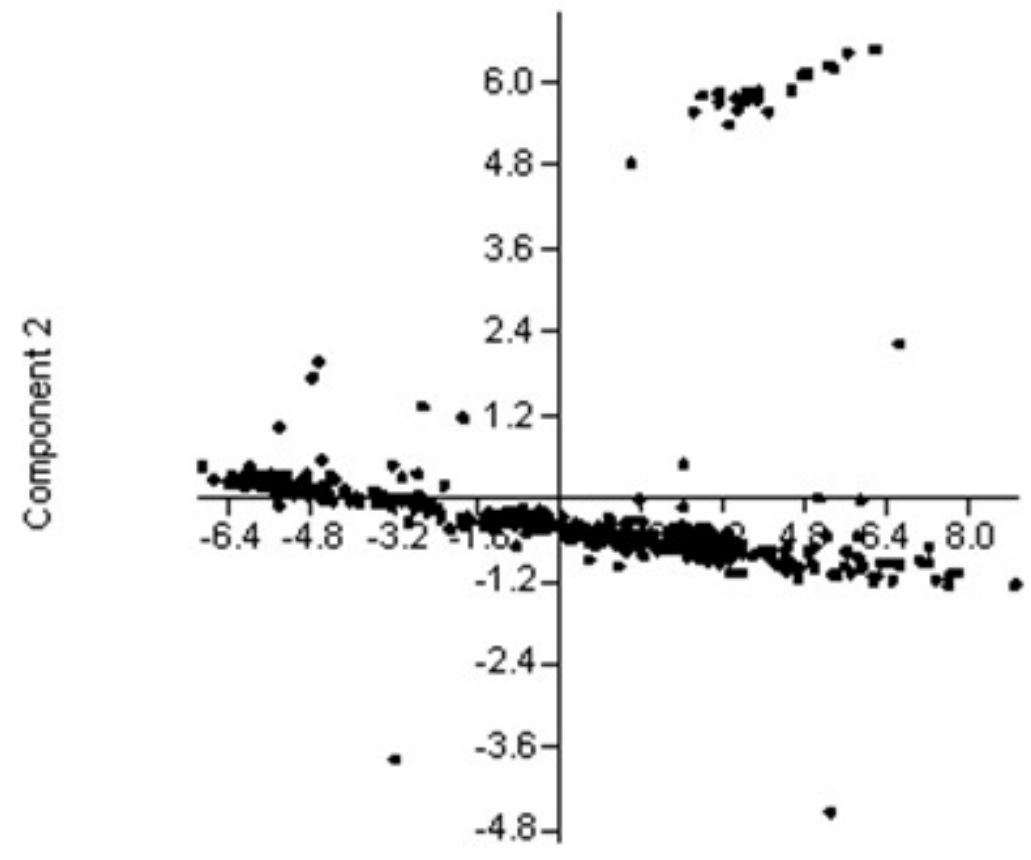

\section{Component 1}

Figure 7. Scatter diagram of principle component 1 versus principle component 2. 


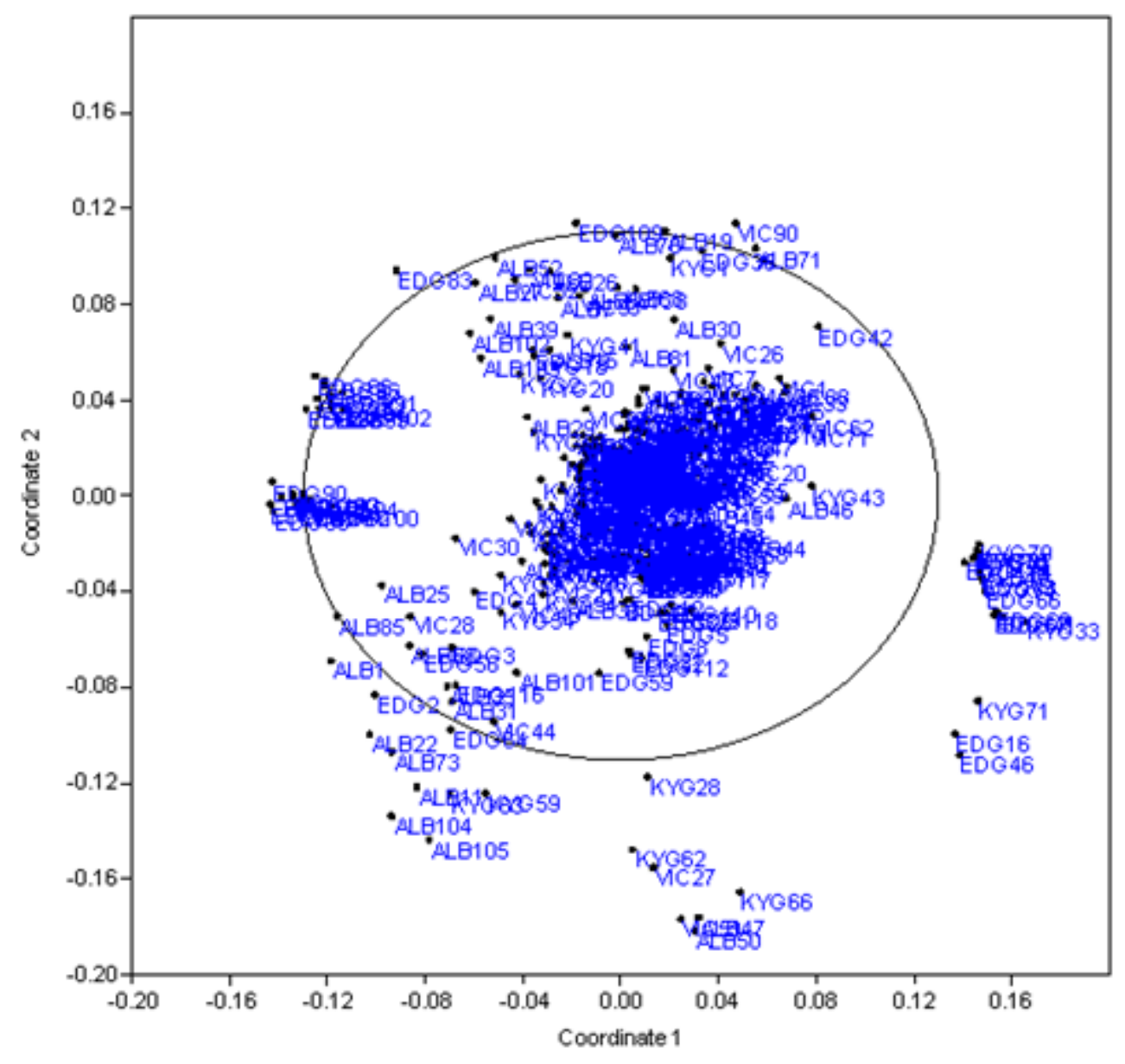

Figure 8. Non-metric Multidimensional scaling with the similarity measure as 'correlation'.

phylogenetics as shown by the dendrogram of a maximu parsimony tree (Fig. 10) constructed using the computer software 'PAST' that grouped or revealed different clusters of the sampled Nile tilapia from Ugandan major water bodies. The multidimensional scaling of the sampled Nile tilapia of Uganda's major lakes also revealed that the fish clustered in two groups, one more dominant than the other (Fig. 9).

\section{Discussion}

The major aim of PCA is to reduce the many variables to a small number of derived variables or components that adequately summarises the information and can be used for further analysis (Smith, 2002). The sampled Nile tilapia from the different lake systems clustered into one large group and one minor group. Apparently there is minimal differentiation between the native populations from the 


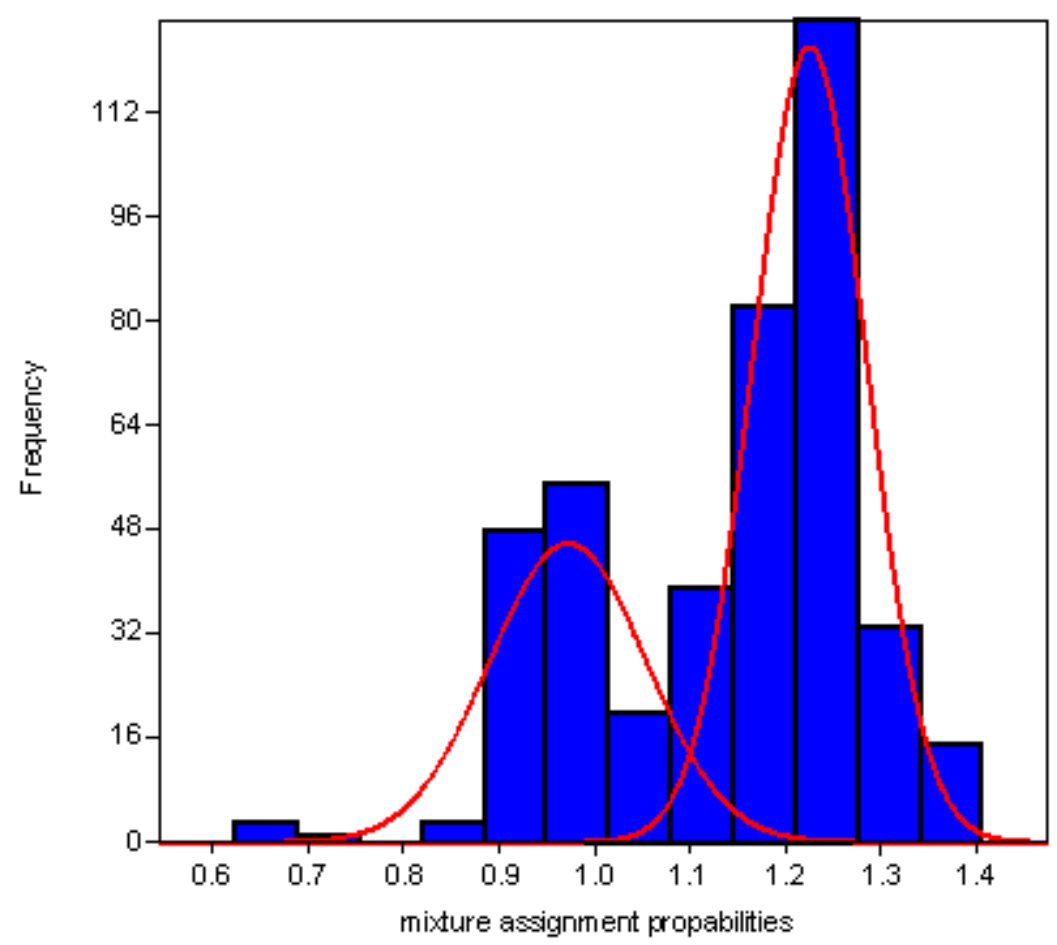

Figure 9. Graph of ratio of variable DFL showing normal curves of the probable 2 groupings of sampled Nile tilapia of major lakes in Uganda generated after PCA under 'PAST'.

western rift lakes, Edward, George and Albert and the introduced populations of the Lake Victoria region waters, that is, lakes Victoria and Kyoga (Fig. 1). This is mostly because the introductions were only done recently in the 1950s and 1960s (Mwanja and Mwanja, 2008), period that is not long enough to allow for morphological differentiation. The minor cluster could be most probably be crossing of the Nile tilapia and other tilapia species, especially in the introduced environs or interactions between Nile tilapia and the farmed escapees that have been inbred for long (Mwanja and Mwanja, 2009). There is need to follow up and compare these findings with molecular characterisation to obtain a better resolution, as use of a combination of morphological and molecular markers is said to give the best results (Weins, 2004).

The second aim of PCA is to reveal patterns in the data, especially among the objects, that could not be found by analysing each variable separately (Smith, 2002). One way of detecting these patterns is to plot the objects in a multidimensional space using the derived variables and use of a dendrogram. The sampled Nile tilapia data, when subjected multidimensional scaling, it was revealed that majority of the sampled Nile tilapia from the different lake systems clustered in one major group. This also most probably indicates that Nile tilapia from Uganda's major water bodies is not morphologically differentiated. This was further supported by the mixture analysis 


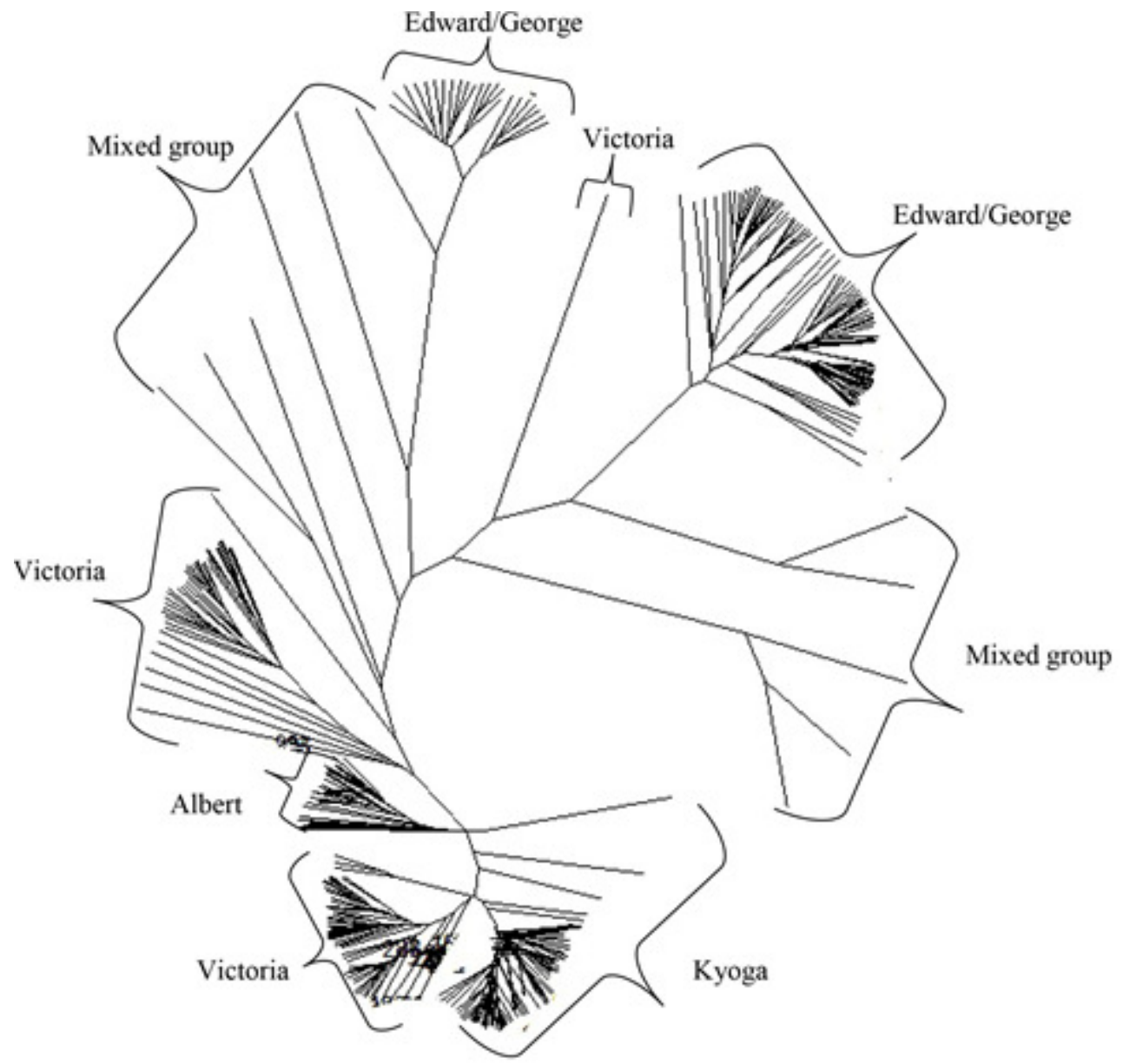

Figure 10. Dendogram showing the phylogenetics relatuionships of the different strains of Nile tilapia in the major water bodies of Uganda.

graph based on one of the variables that contributed most to the morphological variation, the dorsal fin length (DFL), that placed the sampled Nile tilapia into one major group and one smaller group (Fig. 9). The dendogram of parsimonious tree that is used to indicate the morphological phylogenetics (Mwanja et al., 2013), placed the sampled Nile tilapia into five major clusters - each of the first four having individuals mostly from one of the different lake systems, that is Albert, Kyoga, Edward-George and Victoria systems (Fig. 10). The dendogram groups the Victoria and Kyoga strains nearer to the Albert strains, compared to the Edward/George strain; which is most probably explained by the fact that the source of introductions of Nile tilapia into lakes Kyoga and Victoria was Lake Albert (Mwanja et al., 2014). The fifth cluster had a mixture of individuals from all four lake systems (Fig. 10). The smaller group above and the mixed cluster indicated by the dendogram, may be due to genetic swamping of other tilapia species by the versatile Nile tilapia (Mwanja et al., 2012) and/or due to farmed escapees into the 
wild that have been inbred for long times (Mwanja and Mwanja, 2009).

\section{Conclusion}

Nile tilapia of Uganda major water bodies exhibits little morphological differentiation, even with the introductions made to the LVR waters five decades ago. If there are different strains of Nile tilapia in the country, then they cluster according to the different source lake systems. Strain identification will require use of molecular markers for more clear and definitive resolution. The findings will be combined with on-going molecular characterization in an attempt to definitely classify the populations of $O$. niloticus in Ugandan major water bodies. Identified taxa/strains will be subjected to performance trials to aid choice of best performing taxa/strains for use in the enhancement of genetic integrity of farmed Nile tilapia in Uganda and the region.

\section{Acknowledgement}

This study was funded through ATAAS project by the World Bank and Government of Uganda and managed locally by the National Agriculture Research Organisation (NARO). We thankful to all staff at NaFIRRI for their support and advice and our transport officers for making sure we get to our different destinations safely and timely whenever we were out on field trips.

\section{References}

Fuerst, P.A., Mwanja, W.W. and Kaufman, L. 2000. The Genetic history of the introduced Nile Tilapia of lake Victoria (Uganda - E. Africa): The populations structure of Oreochromis niloticus (Pisces:Cichlidae) revealed by DNA microsatellite markers. In: International Symposium on Tilapia in Aquaculture, 5., 2000. Proceedings. Rio de Janeiro: Ista, 2000. pp. 30-40.

Hammer, O., Harper, D. A. T and Ryan, P. D. 2001. Paleontological statistics software package for education and data analysis. Paleontol Electronica 4(1) (4): 9

Mwanja, W.W. 2005. National Aquaculture Sector Overview Uganda. National Aquaculture Sector Overview Fact Sheets. FAO Inland Water Resources and aquaculture Service (FIRI). Rome, FAO. available at: http://www.fao.org/figis/servlet/ static?dom $=$ countrysector $\& \mathrm{xml}$ =naso_uganda.xml. Accessed May 25 2014.

Mwanja, M. T. and Mwanja, W. W. 2008. Preliminary results of the analysis of the population structure of the Nile perch (ILates niloticus Linnaeus, 1758) of lake Victoria using microsatellite markers. African Journal of Biotechnology 7 (16): 2885-2892.

Mwanja, T. M. and Mwanja, W. W. 2009. Escape of farmed tilapiines into the wild and entry of wild forms in fishponds, and possible interaction between wild and farmed tilapiines from a sample of smallholder farms in Central Uganda. African Journal of Ecology 47:469-475.

Mwanja, W.W., Fuerst, P.A. and Kaufman, L. 2012. Reduction of the "ngege", Oreochromis esculentus (Teleostei: Cichlidae) populations, and resultant population genetic status in the Lake Victoria Region. Uganda Journal of Agricultural Sciences 13 (2): 65-82. 
Mwanja, M.T., Mwanja, W.W., genetic improvement programs in Nile Muwanika, V., Masembe, C. and tilapia (Oreochromis niloticus). Nyakaana, S. 2013. Evolutionary Aquaculture 269, 187-199.

history of Nile perch Lates sp. inferred Smith, L. I. 2002. A Tutorial on Principal from mitochondrial DNA variation Components Analysis. http://kybele. analyses. Zoological Studies 52(59): $\quad$ psych.cornell.edu/<"edelman/Psych$1-12$.

Mwanja, M.T., Muwanika, V.B., Masembe, C., Mwanja, W.W. and Nyakaana, S. 2014. Microsatellite DNA analyses reveal population subdivisions among the recently introduced Nile perch (Lates spp.) in Lake Victoria. African Zoology 49(2):181-194.

Ponzoni R.W., Nguyen N.H. and Khaw H.L. 2007. Investment appraisal of 465-Spring-2003/PCA-tutorial.pdf Accessed on June 04, 2014.

Trewavas, E. (Ed.). 1983. Tilapiine fishes of Genera Sarotherodon, Oreochromis and Danakila. British Museum (Natural History) publication. p. 878 .

Weins, J.J. 2004. The role of morphological data in preconstruction. Systematic Biologists 53(4):653-661. 